\title{
Prognostic characteristics and body mass index in patients with pulmonary embolism: does size matter?
}

\author{
Ludo F.M. Beenen (10) ${ }^{1}$, Luuk J.J. Scheres (10) ${ }^{2}$, Jaap Stoker (10) ${ }^{1}$ and \\ Saskia Middeldorp (10)
}

Affiliations: ${ }^{1}$ Dept of Radiology and Nuclear Medicine, Academic Medical Center, University of Amsterdam, Amsterdam, The Netherlands. ${ }^{2}$ Dept of Vascular Medicine, Academic Medical Center, University of Amsterdam, Amsterdam, The Netherlands.

Correspondence: Ludo F.M. Beenen, Dept of Radiology and Nuclear Medicine, Academic Medical Center University of Amsterdam, Meibergdreef 9, 1105 AZ Amsterdam, The Netherlands.

E-mail: l.f.beenendamsterdamumc.nl

\section{ABSTRACT}

Objective: The aim of this study was to explore the impact of body mass index (BMI) on prognostic indicators and clinical outcomes in patients with pulmonary embolism.

Methods: Patients with pulmonary embolism from the Hokusai venous thromboembolism (VTE) randomised clinical trial that compared two anticoagulant regimens were followed-up for 1 year $(\mathrm{n}=1911)$. Patients were analysed with regard to World Health Organization (WHO) BMI categories at baseline (underweight $(<18.5)$, normal $(18.5$ to $<25)$, overweight $(25$ to $<30)$, obese I $(30$ to $<35)$, obese II $(35$ to $<40)$, and obese III $(\geqslant 40)$ ). Clinical and radiological prognostic characteristics for right ventricular dysfunction and adverse events were assessed with normal weight as a reference. Clinical outcomes were mortality, recurrent VTE, hospitalisation, bleeding and overall adverse events.

Results: The relationship between BMI categories and both prognostic parameters and clinical outcomes showed U-shaped curves. Adjusted odds ratios (aORs) were highest in patients who were grade III obese for both clinical parameters (N-terminal pro-brain natriuretic peptide (NT-proBNP) $>600$ and simplified pulmonary embolism severity index (sPESI) $\geqslant 1 ; 2.9$ and 1.6), and radiological parameters (pulmonary trunk $>29 \mathrm{~mm}$, right-to-left-ventricular ratio $>1.0$, and central emboli; $\mathrm{aOR}=4.3,2.1$ and 2.3). Bleeding was observed more frequently in the higher categories of obesity. In patients who were underweight, for NT-proBNP $>600$ and $\mathrm{sPESI} \geqslant 1$ the aORs were 2.6 and 2.5 , respectively; however, no major bleeding occurred in this category.

Conclusion: Several clinical and radiological prognostics characteristics and right ventricular dysfunction in pulmonary embolism are not evenly distributed among BMI categories. This is reflected in a trend towards worse outcomes in patients who are overweight and underweight.

@ERSpublications

Overweight patients with pulmonary embolism have a higher risk of heart dysfunction and worse outcomes http://bit.ly/2Pwtln0

Cite this article as: Beenen LFM, Scheres LJJ, Stoker J, et al. Prognostic characteristics and body mass index in patients with pulmonary embolism: does size matter? ERJ Open Res 2020; 6: 00163 2019 [https://doi.org/10.1183/23120541.00163-2019].

This article has supplementary material available from openres.ersjournals.com

The Hokusai venous thromboembolism study is registered at www.clinicaltrials.gov with identifier number NCT00986154. Data sharing will be in accordance with the study protocol (Daichii Sankyo), protocol DU176b-D-U305, available as supplementary material for the original publication ( $N$ Engl J Med 2013; 369: 1406-1415). The investigator/ investigational site will permit study-related monitoring, audits, IRB/IEC review and regulatory inspections by providing direct access to source data/documents. Direct access includes permission to examine, analyse, verify and reproduce any records and reports that are important to the evaluation of a clinical study.

Received: 25 June 2019 | Accepted after revision: 29 Oct 2019

Copyright $\odot$ ERS 2020. This article is open access and distributed under the terms of the Creative Commons Attribution Non-Commercial Licence 4.0. 


\section{Introduction}

Patients with pulmonary embolism (PE) who are at extremes of body weight pose specific clinical considerations with regard to diagnosis, treatment and prognosis. Patients who are obese are at increased risk for both deep vein thrombosis (DVT) and PE compared to patients with a normal body mass index (BMI; weight in kilograms divided by height in metres squared) [1-3]. This risk increases with increasing BMI $[4,5]$. Potential causal mechanisms for increased risk of venous thrombosis by obesity are venous stasis, chronic inflammation, adipokines, increased coagulation activity, decreased fibrinolytic activity, and procoagulant microparticles [6].

Regarding treatment, it is debated whether the patients at extremes in body weight should receive modified treatment regimens [7]. Because of limited clinical data available for patients who are obese, the International Society on Thrombosis and Haemostasis (ISTH) guidance document advises against the use of direct oral anticoagulants in patients with a body weight higher than $120 \mathrm{~kg}$ or a BMI higher than 40 [8]. Although currently unfractioned heparin with activated partial thromboplastin time monitoring for patients with severe obesity is recommended [9], an expert panel recently expressed the urgent need for data on heparin regimens in all patients who are obese [7]. This becomes even more prominent with the alarming increase in people who are overweight worldwide [10].

Remarkably, with regard to diagnosis and prognosis, knowledge of the impact of BMI on clinical presentation and clot characteristics and burden is even more limited. Unfortunately, even in large randomised trials on efficacy of anticoagulation in patients with venous thromboembolism (VTE) no subgroup analysis on body weight or BMI has been performed to provide methodologically robust data on this subject. Therefore, how this could reflect on work-up and prognosis is not exactly known. Should BMI be a modifier for individual patient-tailored care? Does body size matter?

Our hypothesis was that in patients with PE clot characteristics and prognosis are different at the extremes of BMI. The aim of this study was to explore the impact of body size on presentation, prognostic characteristics and outcome of patients with PE in computed tomography (CT) pulmonary angiography (CTPA). Therefore, we studied in a large cohort of patients with PE established clinical and radiological parameters associated with right ventricular dysfunction and mortality, and stratified them according to BMI categories.

\section{Materials and methods \\ Patients and study design}

This present study is a post hoc analysis of the Hokusai VTE study, a large international randomised clinical trial in which two anticoagulant regimens were compared in patients with VTE (ClinicalTrials.gov identifier: NCT00986154) [11, 12]. In short, eligible patients were aged 18 years or older and had acute symptomatic DVT and/or PE. Patients were excluded in case of contraindication to heparin or warfarin, severely impaired renal function or pregnancy. The Hokusai VTE trial did not exclude patients based on body weight. The institutional review board at each participating centre approved the general study protocol, and all patients provided written informed consent. Follow-up was 12 months, covering the in-hospital period as well as regular outpatient clinic controls, and patients on and off anticoagulant treatment. Adverse events were noted on separate forms, as well as whether these were related to PE. An independent committee adjudicated all predefined outcomes. In the trial, in the two treatment arms there was no difference in hazard ratio between patients with a body weight of $100 \mathrm{~kg}$ or less, and those over $100 \mathrm{~kg}$; no further detailed analyses were performed for high body weight groups [11]. For the current analysis all patients with PE, either with or without DVT, were included. Excluded were patients not evaluated by CTPA, or when images were not available in DICOM format or inaccessible for reading in the image viewer [12].

\section{Data collection}

All clinical and radiological data were anonymised, and centrally registered with double data entry by an independent trial data management agency. Clinical data were retrieved from the original case report form (CRF). In all patients NT-proBNP levels were measured at baseline. All data for the present analysis had been collected and assessed prospectively before the trial data lock.

CT data were acquired from the local participating centres, using local settings and protocols, with a wide variety of CT scanners, from basic to high-end CT. Anonymised patient images from the central database were evaluated by a radiologist (LB) with 12 years of experience in cardiovascular imaging supported by a dedicated research assistant, both blinded for patient details and clinical information. For image reading a commercially available image viewer was used (eFilm Workstation for Windows version 3.4.0, Build 10, Merge Technologies Inc., Milwaukee, WI, USA). Images were primarily read in axial sections with additional support of multiplanar reformatting. Standard pulmonary angiography, mediastinal and lung 
parenchyma window settings were used, with individual adaptation if deemed necessary. Data were registered on a specially designed CRF.

We investigated body size according to the BMI categories as classified by the World Health Organization (WHO): underweight $(<18.5)$, normal $(18.5$ to $<25)$, overweight $(25$ to $<30)$, obese I $(30$ to $<35)$, obese II $(35$ to $<40)$, and obese III $(\geqslant 40)$.

\section{Study outcomes: prognostic characteristics and clinical outcomes}

Both clinical and radiological prognostic characteristics for right ventricular dysfunction and adverse events were assessed. For baseline NT-proBNP a value of $\geqslant 600 \mathrm{pg} \cdot \mathrm{mL}^{-1}$ at baseline was considered abnormal [9]; for sPESI calculations the arterial oxyhaemoglobin saturation $<90 \%$ was not registered; this item was considered positive if patient required oxygen administration. The following radiological parameters for right ventricular dysfunction (RVD) were assessed: transverse diameter of the right and left ventricle (axial view) and pulmonary trunk (PT); bowing of the interventricular septum (negative, D-shaped/neutral, positive) and reflux of contrast medium in the intrahepatic veins). For the ventricular diameters, the largest cross-sectional distance between ventricular surfaces was taken. The PT was measured at its largest transverse diameter. All continuous variables were noted in millimetres where applicable. The right-to-left ventricular $(\mathrm{RV} / \mathrm{LV})$ ratios were calculated by dividing the values of respective transverse diameters. The obtained values were then dichotomised at regular used thresholds (RV/LV $>1.0$; PT $>29 \mathrm{~mm}$ ). Interventricular septum bowing was considered present when the septum was curved to the left ventricle or flattened. Backflow was considered positive if contrast medium reflux occurred into the intrahepatic veins; only into the inferior caval vein was considered negative.

Clinical outcomes for the study were mortality, recurrent VTE, hospitalisation, bleeding and overall adverse events. Outcome events were analysed after a follow-up of 1 year.

\section{Statistical analysis}

Descriptive statistics are displayed as mean \pm SD for normally distributed variables and median \pm interquartile ranges (IQR, 25th to 75th percentile) for non-normally distributed variables. For comparison of binary outcomes, the Chi-squared test for dichotomous variables was used. Between the groups, categorical variables were compared using the Chi-squared test for trend and for continuous data, by t-test or Mann-Whitney U-test if non-normally distributed. A p-value $<0.05$ was considered statistically significant. We used logistic regression models to estimate odds ratios (ORs) with 95\% confidence intervals (CIs) to investigate the association between the outcome variables and the BMI categories. In addition, where appropriate, we adjusted these analyses for age and sex. All statistical analyses were performed in SPSS version 23 (SPSS Inc., Chicago, IL, USA) and figures were designed in GraphPad Prism version 7.00 for Windows (GraphPad Software, La Jolla California, CA, USA).

\section{Results}

Baseline characteristics are displayed in table 1. The initial study group consisted of 1950 patients with PE. In all 1950 patients, baseline weight was available, but in 39 patients (2.0\%) body height was not known. Hence baseline BMI could only be calculated in 1911 patients, comprising the study group for further analyses. Of these 1911 patients, 493 (25.8\%) had a normal BMI (table 2). The majority of patients (1389; $72.7 \%)$ had a $\mathrm{BMI}>25$ and obesity $(\mathrm{BMI}>30)$ was present in $670(35.1 \%)$ patients. A small proportion of patients $(29 ; 1.5 \%)$ was underweight.

With regard to risk factors for VTE, 372 patients (19.5\%) had undergone recent surgery and 415 patients (21.7\%) had a history of VTE. Arterial cardiovascular risk factors (e.g. smoking and hypertension) were present in a substantial proportion of patients: hypertension was present in 810 (42.4\%) patients, 199 (10.4\%) patients had diabetes mellitus, and 314 (16.4\%) patients had a history of cardiovascular disease.

The overall trend, clinical, radiological and outcome parameters are displayed in figures 1 and 2 for all patients according to the BMI categories. Both patterns for $\mathrm{N}$-terminal pro-brain natriuretic peptide (NT-proBNP), PE severity index (sPESI) and enlarged PT showed a U-shaped curve, with lowest percentages in the normal BMI range, and were higher for patients who were overweight as well as underweight. Other parameters such as enlarged RV/LV ratio and central clot location showed a direct association with increasing BMI.

The associations between the prognostic characteristics and BMI categories are shown in table 3 and detailed distribution of parameters and outcomes in supplementary table 4. There was an apparent exposure-response relationship between BMI category and the proportion of patients with NT-proBNP $>600$, sPESI high risk, PT $>29 \mathrm{~mm}, \mathrm{RV} / \mathrm{LV}>1$ and presence of central emboli. The OR for NT-proBNP $>600$ increased up to $2.90(95 \% \mathrm{CI} 1.79-4.70)$ at $\mathrm{BMI}>40$. For the other prognostic characteristics the ORs 
TABLE 1 Baseline characteristics

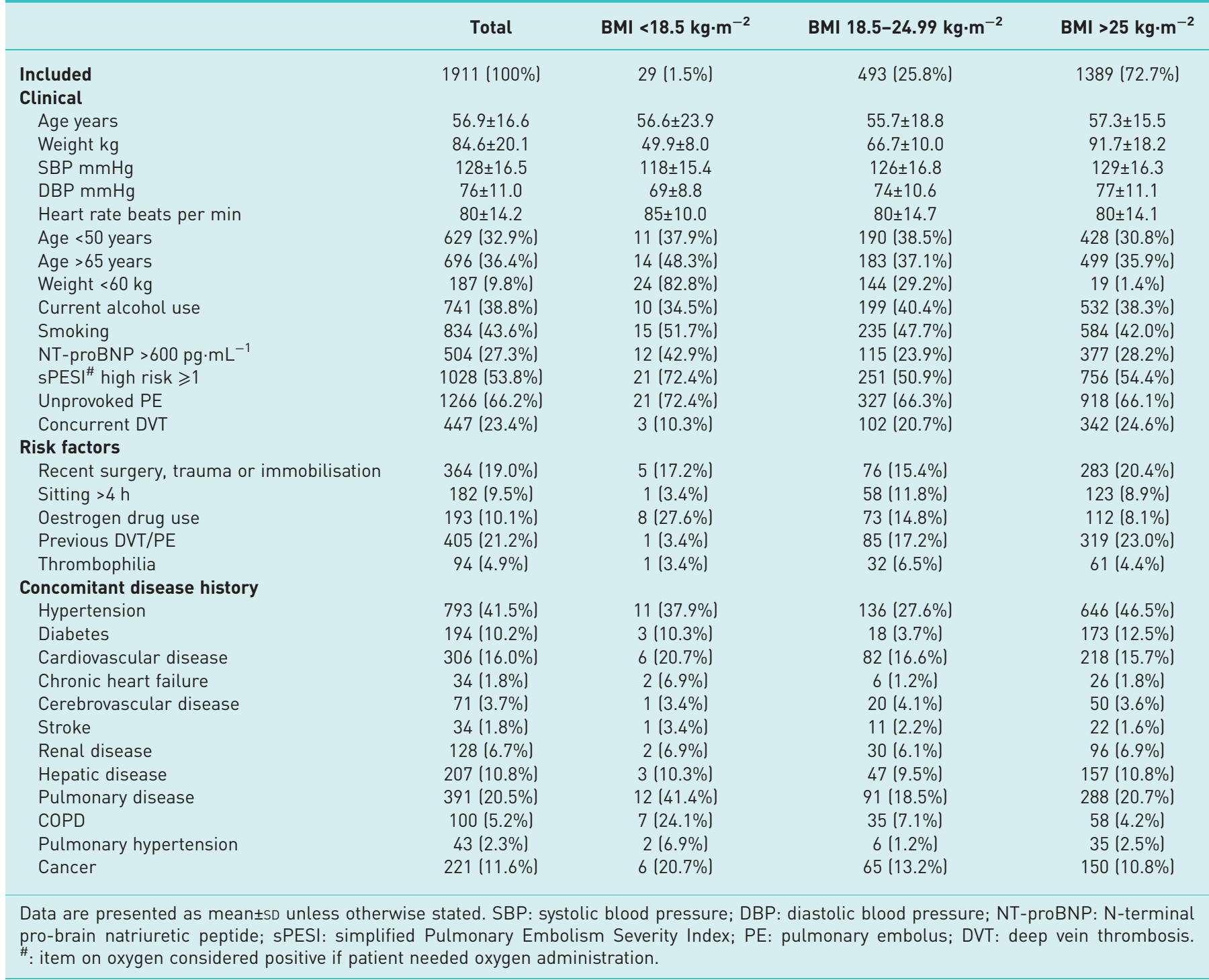

for $\mathrm{BMI}>40$ compared to normal BMI were OR 4.32 (95\% CI 2.73-6.83) for PT >29 mm, 2.12 (95\% CI 1.34-3.33) for $\mathrm{RV} / \mathrm{LV}>1.0,2.34$ (95\% CI 1.51-3.62) for central location of the emboli and 1.55 (95\% CI 1.00-2.41) for the sPESI high risk category.

TABLE 2 Distribution of patients according to World Health Organization body mass index (BMI) categories ( $\mathrm{N}=1911)$

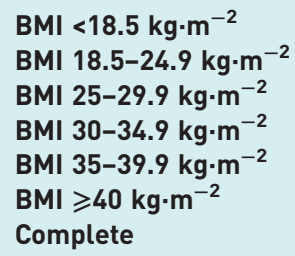

\#: body height was not available in $39(2.0 \%)$ out of 1950 patients so in these patients, BMI could not be

calculated.

$29(1.5 \%)$

$493(25.8 \%)$

$717(37.5 \%)$

$414(21.7 \%)$

$154(8.1 \%)$

$104(5.4 \%)$

$1950^{\#}$ 

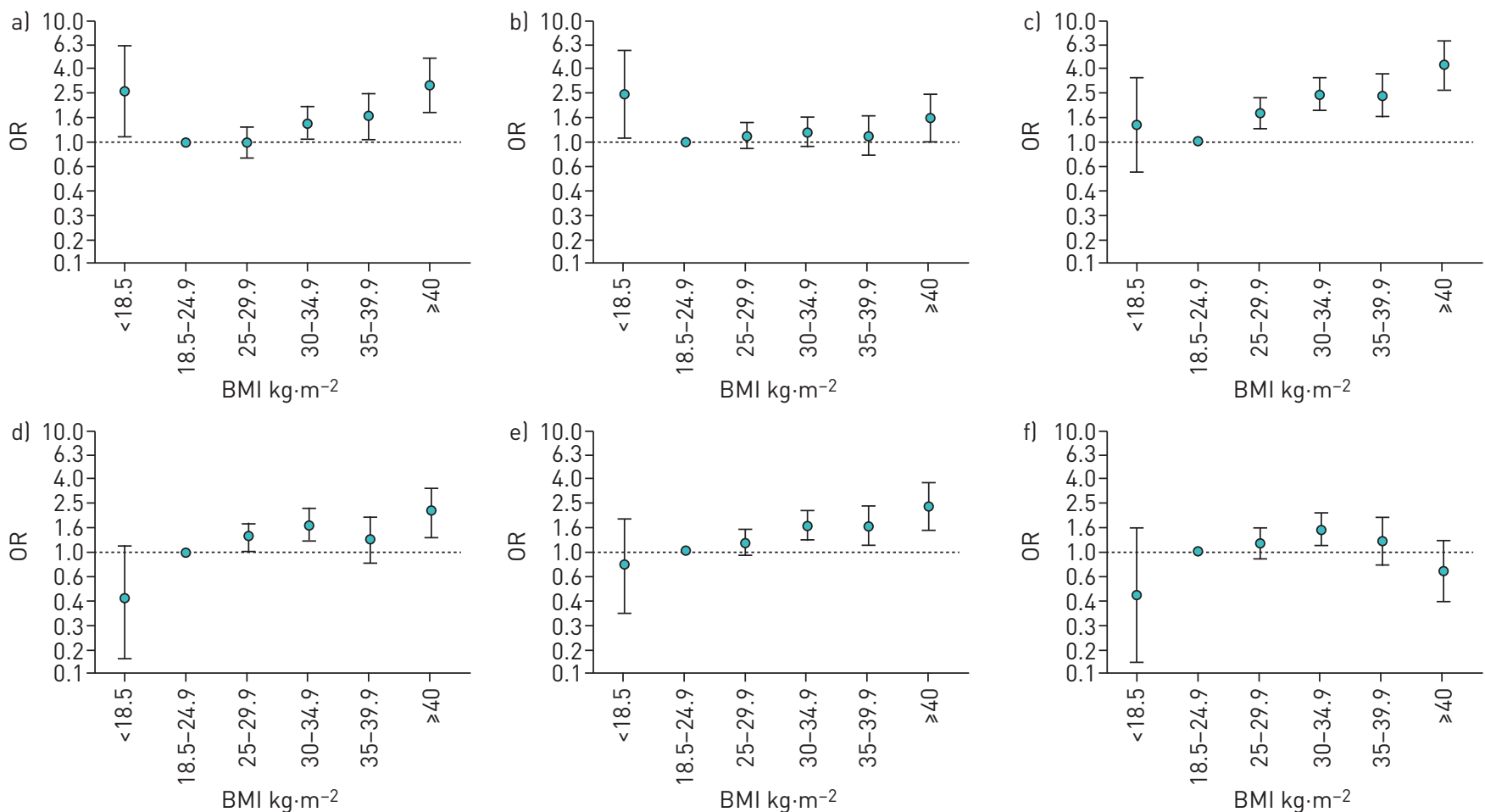

FIGURE 1 Association between body mass index (BMI) categories and clinical and radiological parameters with $\mathrm{BMI} 18.5-24.9 \mathrm{~kg} \cdot \mathrm{m}^{-2}$ as a reference. Odds ratios for a) N-terminal pro-brain natriuretic peptide, b) high-risk simplified pulmonary embolism severity index score, c) pulmonary trunk $>29 \mathrm{~mm}$, d) right/left ventricular diameter ratio $>1.0$, e) central embolism and d) concurrent deep venous thrombosis are shown. Error bars present $95 \%$ confidence intervals.
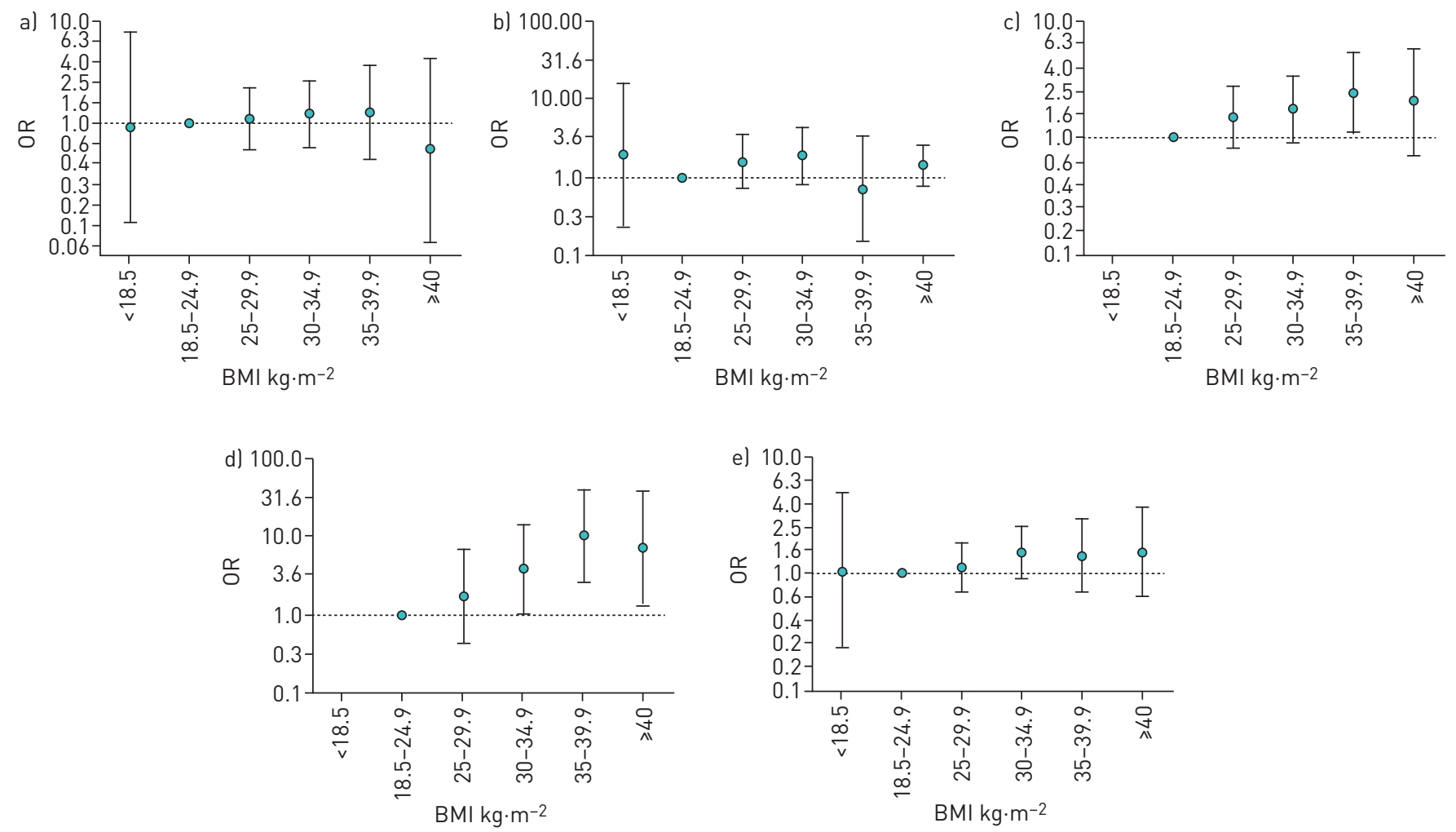

FIGURE 2 Association between body mass index (BMI) categories and outcomes with BMI $18.5-24.9 \mathrm{~kg} \cdot \mathrm{m}^{-2}$ as reference. Odds ratios for a) death, b) recurrent venous thromboembolism, c) hospitalisation, d) bleeding and e) all adverse events are shown. Error bars represent $95 \%$ confidence intervals. 
TABLE 3 Odds ratios for clinical and radiological parameters and outcomes according to World Health Organization body mass index (BMI) categories

\section{Patients}

Unadjusted OR $(95 \% \mathrm{Cl})$

Adjusted $^{\#}$ OR $(95 \% \mathrm{Cl})$

\section{Clinical and radiological parameters \\ NT-proBNP $>600 \mathrm{pg} \cdot \mathrm{mL}^{-1}$}

$\mathrm{BMI}<18.5 \mathrm{~kg} \cdot \mathrm{m}^{-2}$

BMI $18.5-24.9 \mathrm{~kg} \cdot \mathrm{m}^{-2}$

BMI $25.0-29.9 \mathrm{~kg} \cdot \mathrm{m}^{-2}$

BMI $30.0-34.9 \mathrm{~kg} \cdot \mathrm{m}^{-2}$

BMI $35.0-39.9 \mathrm{~kg} \cdot \mathrm{m}^{-2}$

$\mathrm{BMI}>40 \mathrm{~kg} \cdot \mathrm{m}^{-2}$

sPESI high risk

$\mathrm{BMI}<18.5 \mathrm{~kg} \cdot \mathrm{m}^{-2}$

BMI $18.5-24.9 \mathrm{~kg} \cdot \mathrm{m}^{-2}$

BMI $25.0-29.9 \mathrm{~kg} \cdot \mathrm{m}^{-2}$

BMI $30.0-34.9 \mathrm{~kg} \cdot \mathrm{m}^{-2}$

BMI $35.0-39.9 \mathrm{~kg} \cdot \mathrm{m}^{-2}$

$\mathrm{BMI}>40 \mathrm{~kg} \cdot \mathrm{m}^{-2}$

Pulmonary trunk $>29 \mathrm{~mm}$

$\mathrm{BMI}<18.5 \mathrm{~kg} \cdot \mathrm{m}^{-2}$

BMI $18.5-24.9 \mathrm{~kg} \cdot \mathrm{m}^{-2}$

BMI $25.0-29.9 \mathrm{~kg} \cdot \mathrm{m}^{-2}$

BMI $30.0-34.9 \mathrm{~kg} \cdot \mathrm{m}^{-2}$

BMI $35.0-39.9 \mathrm{~kg} \cdot \mathrm{m}^{-2}$

$\mathrm{BMI}>40 \mathrm{~kg} \cdot \mathrm{m}^{-2}$

$\mathrm{RV} / \mathrm{LV}>1.0$

$\mathrm{BMI}<18.5 \mathrm{~kg} \cdot \mathrm{m}^{-2}$

BMI $18.5-24.9 \mathrm{~kg} \cdot \mathrm{m}^{-2}$

BMI $25.0-29.9 \mathrm{~kg} \cdot \mathrm{m}^{-2}$

BMI $30.0-34.9 \mathrm{~kg} \cdot \mathrm{m}^{-2}$

BMI $35.0-39.9 \mathrm{~kg} \cdot \mathrm{m}^{-2}$

$\mathrm{BMI}>40 \mathrm{~kg} \cdot \mathrm{m}^{-2}$

Central embolus

$\mathrm{BMI}<18.5 \mathrm{~kg} \cdot \mathrm{m}^{-2}$

BMI $18.5-24.9 \mathrm{~kg} \cdot \mathrm{m}^{-2}$

BMI $25.0-29.9 \mathrm{~kg} \cdot \mathrm{m}^{-2}$

BMI $30.0-34.9 \mathrm{~kg} \cdot \mathrm{m}^{-2}$

BMI $35.0-39.9 \mathrm{~kg} \cdot \mathrm{m}^{-2}$

$\mathrm{BMI}>40 \mathrm{~kg} \cdot \mathrm{m}^{-2}$

Concurrent DVT

$\mathrm{BMI}<18.5 \mathrm{~kg} \cdot \mathrm{m}^{-2}$

BMI $18.5-24.9 \mathrm{~kg} \cdot \mathrm{m}^{-2}$

BMI $25.0-29.9 \mathrm{~kg} \cdot \mathrm{m}^{-2}$

BMI $30.0-34.9 \mathrm{~kg} \cdot \mathrm{m}^{-2}$

BMI $35.0-39.9 \mathrm{~kg} \cdot \mathrm{m}^{-2}$

$\mathrm{BMI}>40 \mathrm{~kg} \cdot \mathrm{m}^{-2}$

\section{Outcomes \\ Death}

$\mathrm{BMI}<18.5 \mathrm{~kg} \cdot \mathrm{m}^{-2}$

BMI $18.5-24.9 \mathrm{~kg} \cdot \mathrm{m}^{-2}$

BMI $25.0-29.9 \mathrm{~kg} \cdot \mathrm{m}^{-2}$

BMI $30.0-34.9 \mathrm{~kg} \cdot \mathrm{m}^{-2}$

BMI $35.0-39.9 \mathrm{~kg} \cdot \mathrm{m}^{-2}$

$\mathrm{BMI}>40 \mathrm{~kg} \cdot \mathrm{m}^{-2}$

Recurrent VTE

$\mathrm{BMI}<18.5 \mathrm{~kg} \cdot \mathrm{m}^{-2}$

BMI $18.5-24.9 \mathrm{~kg} \cdot \mathrm{m}^{-2}$

BMI $25.0-29.9 \mathrm{~kg} \cdot \mathrm{m}^{-2}$

BMI $30.0-34.9 \mathrm{~kg} \cdot \mathrm{m}^{-2}$

BMI $35.0-39.9 \mathrm{~kg} \cdot \mathrm{m}^{-2}$

$\mathrm{BMI}>40 \mathrm{~kg} \cdot \mathrm{m}^{-2}$
$12(42.8 \%)$

$115(24.0 \%)$

$162(23.4 \%)$

$124(31.2 \%)$

50 (34.0\%)

$41(41.0 \%)$

$21(72.4 \%)$

$251(51.0 \%)$

$375(52.4 \%)$

$230(55.7 \%)$

$84(54.5 \%)$

$66(63.5 \%)$

$8(27.6 \%)$

$106(21.5 \%)$

$232(32.4 \%)$

$168(40.7 \%)$

$59(38.3 \%)$

$49(47.1 \%)$

$4(13.8 \%)$

$130(26.4 \%)$

$231(32.3 \%)$

$157(38.0 \%)$

$48(31.2 \%)$

$41(39.4 \%)$

7 (24.1\%)

$143(29.1 \%)$

234 (32.7\%)

$167(40.4 \%)$

$62(40.3 \%)$

$49(47.1 \%)$

$3(10.3 \%)$

$102(20.7 \%)$

$170(23.7 \%)$

$121(29.3 \%)$

$36(23.4 \%)$

$15(14 \%)$

$1(3.4 \%)$

$14(2.8 \%)$

$22(3.1 \%)$

$14(3.4 \%)$

$5(3.2 \%)$

$1(1.0 \%)$

$1(3.4 \%)$

$9(1.8 \%)$

$21(2.9 \%)$

$14(3.4 \%)$

2 (1.3\%)

$3(2.9 \%)$
$2.38(1.09-5.18)$ 1 (ref.)

$0.97(0.74-1.28)$

$1.44(1.07-1.94)$

$1.64(1.10-2.44)$

$2.21(1.41-3.46)$

$2.52(1.10-5.80)$

1 (ref.)

$1.06(0.84-1.33)$

$1.21(0.93-1.57)$

$1.15(0.80-1.66)$

$1.67(1.08-2.58)$

$1.39(0.60-3.22)$

1 (ref.)

$1.75(1.34-2.28)$

$2.50(1.87-3.34)$

$2.26(1.53-3.34)$

3.24 (2.09-5.04)

$0.45(0.15-1.31)$

1 (ref.)

1.33 (1.03-1.71)

$1.71(1.29-2.27)$

$1.26(0.85-1.88)$

$1.81(1.17-2.81)$

$0.78(0.33-1.86)$

1 (ref.)

$1.19(1.19-0.92)$

$1.66(1.26-2.19)$

$1.65(1.30-2.40)$

2.17 (1.41-3.35)

$0.44(0.13-1.49)$ 1 (ref.)

$1.19(0.90-1.57)$

$1.58(1.17-2.15)$

$1.17(0.76-1.80)$

$0.64(0.36-1.16)$

$1.22(0.16-9.61)$ 1 (ref.)

$1.08(0.55-2.14)$

$1.20(0.56-2.54)$

$1.15(0.41-3.23)$

$0.33(0.04-2.55)$

$1.92(0.24-15.67)$ 1 (ref.)

$1.62(0.74-3.57)$

$1.88(0.81-4.40)$

$0.71(0.15-3.30)$

1.59 (0.42-5.99)
$2.62(1.10-6.23)$ 1 (ref.)

$0.98(0.74-1.31)$

$1.41(1.03-1.93)$

$1.62(91.06-2.48)$

$2.90(1.79-4.70)$

$2.49(1.08-5.75)$

1 (ref.)

$1.11(0.88-1.40)$

$1.23(0.95-1.60)$

$1.13(0.78-1.62)$

$1.55(1.00-2.41)$

$1.36(0.56-3.28)$ 1 (ref.)

$1.66(1.27-2.19)$

$2.44(1.81-3.28)$

$2.37(1.59-3.53)$

$4.32(2.73-6.83)$

$0.40(0.13-1.12)$ 1 (ref.)

$1.31(1.01-1.70)$

$1.66(1.24-2.21)$

$1.24(0.83-1.85)$

2.12 (1.34-3.33)

$0.75(0.31-1.82)$ 1 (ref.)

$1.17(0.91-1.50)$

$1.61(1.22-2.13)$

$1.61(1.10-2.36)$

$2.34(1.51-3.62)$

$0.45(0.13-1.52)$ 1 (ref.)

$1.15(0.87-1.52)$

$1.57(1.16-2.14)$

$1.20(0.78-1.85)$

$0.68(0.38-1.23)$

$0.92(0.11-7.59)$ 1 (ref.)

$1.09(0.55-2.18)$

$1.21(0.57-2.60)$

$1.29(0.45-3.71)$

$0.53(0.07-4.18)$

$1.90(0.23-15.57)$

1 (ref.)

$1.55(0.70-3.42)$

$1.82(0.78-4.25)$

$0.71(0.15-3.34)$

$1.41(0.78-2.53)$ 


\begin{tabular}{|c|c|c|c|}
\hline & Patients & Unadjusted OR $(95 \% \mathrm{CI})$ & Adjusted $^{\#}$ OR $(95 \% \mathrm{CI})$ \\
\hline \multicolumn{4}{|l|}{ Hospitalisation } \\
\hline $\mathrm{BMI}<18.5 \mathrm{~kg} \cdot \mathrm{m}^{-2}$ & $0(0 \%)$ & 0 & 0 \\
\hline BMI $18.5-24.9 \mathrm{~kg} \cdot \mathrm{m}^{-2}$ & $16(3.3 \%)$ & 1 (ref.) & 1 (ref.) \\
\hline BMI $25.0-29.9 \mathrm{~kg} \cdot \mathrm{m}^{-2}$ & $34(4.7 \%)$ & $1.48(0.81-2.72)$ & $1.49(0.81-2.75)$ \\
\hline BMI $30.0-34.9 \mathrm{~kg} \cdot \mathrm{m}^{-2}$ & $23(5.6 \%)$ & $1.75(0.91-3.37)$ & $1.74(0.90-3.35)$ \\
\hline BMI $35.0-39.9 \mathrm{~kg} \cdot \mathrm{m}^{-2}$ & $11(7.1 \%)$ & $2.29(1.04-5.04)$ & $2.39(1.08-5.32)$ \\
\hline $\mathrm{BMI}>40 \mathrm{~kg} \cdot \mathrm{m}^{-2}$ & $5(4.8 \%)$ & $1.50(0.54-4.20)$ & $1.99(0.70-5.67)$ \\
\hline \multicolumn{4}{|l|}{ Bleeding } \\
\hline $\mathrm{BMI}<18.5 \mathrm{~kg} \cdot \mathrm{m}^{-2}$ & $0(0 \%)$ & 0 & 0 \\
\hline BMI $18.5-24.9 \mathrm{~kg} \cdot \mathrm{m}^{-2}$ & $3(0.6 \%)$ & 1 (ref.) & 1 (ref.) \\
\hline BMI $25.0-29.9 \mathrm{~kg} \cdot \mathrm{m}^{-2}$ & $7(1.0 \%)$ & $1.61(0.41-6.25)$ & $1.72(0.44-6.74)$ \\
\hline BMI $30.0-34.9 \mathrm{~kg} \cdot \mathrm{m}^{-2}$ & $9(2.2 \%)$ & $3.63(0.98-13.50)$ & $3.82(1.02-14.34)$ \\
\hline BMI $35.0-39.9 \mathrm{~kg} \cdot \mathrm{m}^{-2}$ & $8(5.2 \%)$ & $8.93(2.34-34.10)$ & 9.99 (2.56-38.92) \\
\hline $\mathrm{BMI}>40 \mathrm{~kg} \cdot \mathrm{m}^{-2}$ & $3(2.9 \%)$ & $4.84(0.96-24.33)$ & $7.26(1.37-38.32)$ \\
\hline \multicolumn{4}{|l|}{ All adverse events } \\
\hline $\mathrm{BMI}<18.5 \mathrm{~kg} \cdot \mathrm{m}^{-2}$ & $2(6.9 \%)$ & $1.23(0.279-5.43)$ & $1.08(0.24-4.90)$ \\
\hline BMI $18.5-24.9 \mathrm{~kg} \cdot \mathrm{m}^{-2}$ & $28(5.7 \%)$ & 1 (ref.) & 1 (ref.) \\
\hline BMI $25.0-29.9 \mathrm{~kg} \cdot \mathrm{m}^{-2}$ & $47(6.6 \%)$ & $1.16(0.72-1.89)$ & $1.15(0.70-1.87)$ \\
\hline BMI $30.0-34.9 \mathrm{~kg} \cdot \mathrm{m}^{-2}$ & $35(8.5 \%)$ & $1.53(0.92-2.57)$ & $1.50(0.89-2.52)$ \\
\hline BMI $35.0-39.9 \mathrm{~kg} \cdot \mathrm{m}^{-2}$ & $12(7.8 \%)$ & $1.40(0.69-2.83)$ & $1.47(0.71-2.94)$ \\
\hline $\mathrm{BMI}>40 \mathrm{~kg} \cdot \mathrm{m}^{-2}$ & $7(6.7 \%)$ & $1.20(0.51-2.82)$ & $1.55(0.65-3.72)$ \\
\hline \multicolumn{4}{|c|}{$\begin{array}{l}\text { BMI }<18.5 \mathrm{~kg} \cdot \mathrm{m}^{-2}, \mathrm{n}=29 ; 18.5-24.9 \mathrm{~kg} \cdot \mathrm{m}^{-2}, \mathrm{n}=492 ; 25.0-29.9 \mathrm{~kg} \cdot \mathrm{m}^{-2}, \mathrm{n}=716 ; 30.0-34.9 \mathrm{~kg} \cdot \mathrm{m}^{-2}, \mathrm{n}=413 ; \\
35.0-39.9 \mathrm{~kg} \cdot \mathrm{m}^{-2}, \mathrm{n}=154 ;>40 \mathrm{~kg} \cdot \mathrm{m}^{-2}, \mathrm{n}=104 \text {. Ref.: BMI } 18.5-24.9 \mathrm{~kg} \cdot \mathrm{m}^{-2} \text {. Proportion was calculated per } \\
\text { BMI category with follow-up up to } 12 \text { months. NT-proBNP: N-terminal pro-brain natriuretic peptide; } \\
\text { sPESI: simplified Pulmonary Embolism Severity Index; RV/LV: right ventricular/left ventricular ratio; DVT: } \\
\text { deep vein thrombosis; VTE: venous thromboembolism. }{ }^{\text {: }} \text { : for age and sex; sPESI only adjusted for sex. }\end{array}$} \\
\hline
\end{tabular}

There were 57 deaths, 50 recurrent VTEs, 89 hospitalisations, 30 major bleedings, and 131 adverse events overall reported during 1 year. For the clinical outcomes an exposure-response relation for risk of hospitalisation, bleeding and adverse events was observed, with the risk of the event increasing with BMI (table 3). The highest risk in the BMI category $>40$ was for bleeding (OR 7.26, 95\% CI 1.37-38.3). Also, for the other clinical outcomes, mortality and recurrent VTE, an increase for the higher BMI categories was observed, as well as for the overall risk of adverse events (figure 2). Interestingly, risk of hospitalisation and major bleeding were not higher in patients who were underweight, although the $95 \%$ CI for this point estimate was wide.

\section{Discussion}

We demonstrated that prognostic characteristics of PE on CTPA are associated with BMI in a category-dependent manner, with the highest risk at the extremes of BMI. Also, for the most important clinical outcomes of mortality and VTE recurrence, an unfavourable trend for the high BMI categories was present, though not statistically significant. Our study highlights the potential importance of assessing BMI as a prognostic indicator when diagnosing and treating patients with PE. Contrary to many other determinants, common demographics such as body size and height are easily obtainable, without any effort or costs, for regular use in daily clinical practice.

A strength of our study is the prospective and rigorous collection of all included data as part of a large international randomised clinical trial. Both imaging data and clinical outcomes were assessed before the data lock and the assessors were blinded for treatment and outcome. We evaluated a broad range of parameters in order to provide a complete, integral picture rather than limiting to a single factor with concurrent restricted impact.

Our study has some limitations. Despite the fact that the number of all included patients is large, the relatively low frequency of events with associated statistical uncertainty prohibits us from drawing firm or definite conclusions, even more so for the underweight category. We did not further adjust for potential confounders like comorbidities and risk factors, as the power to do so was limited by the relatively low number of outcome events. Because of the paucity of literature on this increasingly prominent issue, however, we nevertheless think of it contributing value, as an incentive for further exploration of this topic. 
Also, we are aware that patients included in a randomised controlled trial do not necessarily reflect all those presenting in daily clinical practice, and our results cannot be unconditionally generalised to those with exclusion criteria for the trial, such as patients who are haemodynamically unstable and patients with a limited life expectancy. Lastly, we only used correlation with BMI categories. Although the use of BMI as an obesity measure has been questioned, it is still the most widely used body weight measurement, and is easy to obtain. Apart from BMI, other measures for body size exist, such as body fat percentage, waist circumference and waist-to-hip ratio (not registered in the trial) [5].

A classic U- or J-shaped curve for BMI categories has been reported in a wide variety of pathological and physiological conditions, such as cardiovascular and respiratory disease, stroke and cancer $[10,13,14]$. Our findings suggest that a similar pattern applies to prognostic indicators in patients with PE, with the lowest prevalence of many investigated parameters for the normal weight group, and a higher prevalence at the extremes of body weight. BMI not only was predictive in several clinical and radiological prognostic characteristics associated with RV dysfunction, but also in a similar way with the relevant clinical outcomes. We are not aware of other studies that explored the association between a broad range of prognostic characteristics in PE and BMI categories; only one study reported that patients who are obese in general have reduced levels of NT-proBNP, despite higher LV end-diastolic pressures [15]. As such, it is even more interesting that in patients with PE, NT-proBNP levels tended to be higher in higher BMI categories. Notably, in patients who are obese, adaptations in cardiac structure and function, more specifically differences in RV morphology could develop [16]. These alterations could be induced by increased RV afterload, increased blood volume, hormonal effects, or direct obesity-related myocardial effects [17].

How do our findings fit into the current assessment of patients who are overweight with acute PE? In the Framingham study [18], women who had a fatal PE had a higher body weight than those who died of other causes. On the contrary, several investigators have reported a higher incidence of VTE in patients who are obese but a lower rate of mortality compared to patients who are not obese, even despite the fact that patients who are obese have more comorbidities, a phenomenon referred to as the obesity paradox [19-23]. However, this is also in contrast with large autopsy studies, where in each category of above-normal BMIs, individuals who were obese were more likely to die from PE [24, 25].

Complex relationships exist between body mass indicators, metabolic function and cardiovascular risk. Possibly, clot composition in individuals who are obese might be different from those with normal weight [26]. It has been hypothesised that these clots could become more resistant to fibrinolysis because of higher fibrinogen levels, polycythaemia, and other haematological changes related to obesity [27, 28]. Our observation that patients with higher BMI categories had more central clots could also be a reflection of the different physical properties of the thrombi in obese.

For recurrent VTE, several papers have been published; however, these have conflicting results, as some found no association between obesity and the risk of VTE recurrence [29-32], whereas others found a higher recurrence risk with higher BMI [33, 34]. In our study, confidence intervals for the estimates crossed unity and we therefore cannot give a definitive answer on this matter.

Reports on the other investigated clinical outcomes (hospitalisation, bleeding and overall adverse effects) are scarce, as most often they are used as a composite outcome, or focus on differences between treatment regimens.

Our finding of a trend for increased hospitalisation for patients who were obese is supported by the large Australian 45 and Up cohort study, where the risk of hospitalisation for a wide range of cardiovascular disease subtypes increased with relatively fine increments in BMI. For PE, the age- and sex-adjusted hazard ratio was 1.39 (95\% CI 1.25-1.55) compared to normal BMI [35].

Bleeding complications during treatment of PE are more frequent than recurrent VTE [36]. In the current study a higher incidence of bleeding in the overweight was observed, underlining the importance of this complication. Both for weight and BMI, in the RIETE prospective registry $[19,37]$ as well as in subgroup analysis of the Matisse [29] and EINSTEIN DVT/PE [31] anticoagulation randomised controlled trials no association between body weight or BMI and major bleeding was found. However, analysis was only performed using two or three large categories (patients weighing $<50,50-100 \mathrm{~kg}$ versus $>100 \mathrm{~kg}$, or $\mathrm{BMI}<30$ versus $\geqslant 30$ or $<25,25-30$ and $30-35$ ), and patients who were underweight were included in the normal weight category. Of note, in the RIETE study, patients who were underweight with VTE (or weighing $<50 \mathrm{~kg}$ ) had a significantly higher rate of bleeding complications. This is in contradiction with our findings. A potential explanation could be the difference in selection of patients, or analysis and categorisation study.

For patients who are underweight, studies on other clinical outcomes are scarce. For prognostic characteristics and RVD, no data have been published until now. Patients who are underweight had 
increased mortality compared to those with normal weight [19], but an equal number of fatal PEs. The difficulty for this category is that it can reflect two different populations, those who have been always underweight, and those that due to an underlying condition sustained significant weight loss, such as in cancer, immobility or renal insufficiency, making them susceptible to adverse events. As these people have less adipose tissue, drug pharmacokinetics are probably different.

Our findings of a trend towards worse prognostics in patients who are obese underlines the importance of more patient-centred care [38], in particular with respect to choosing the appropriate anticoagulant therapy for each individual patient. In this way, we can confirm the call for increased awareness on dedicated prophylactic and therapeutic anticoagulant regimens in obesity [7]. Reassuringly, a recent well-sized cohort study suggested similar efficacy and safety between direct oral anti-Xa inhibitors and warfarin in patients who are morbidly obese, although these retrospective findings warrant confirmation in prospective studies [39].

Future directions for study should explore the interaction of obesity and other risk factors for VTE, both for development, presentation, therapeutics and outcomes [40]. Special attention should focus on clinical severity, RVD and risk stratification. As obesity can be regarded a proinflammatory condition, more fundamental research should be directed towards molecular, pathogenic and sex-specific mechanisms responsible for VTE onset, development, and recurrence [41].

In conclusion, we found that several clinical and radiological prognostics characteristics and RVD in PE are not evenly distributed among BMI categories. This is reflected in a trend towards worse outcomes in the patients who are overweight and underweight compared to normal weights. This could be an incentive towards dedicated patient-tailored evaluation and treatment.

Acknowledgements: The current study was performed without any financial support. The original Hokusai VTE study was sponsored and funded by Daiichi Sankyo Pharma Development. We thank Paul Gerrits and Vidhi Dani from ITREAS, Academic Research Organisation, Amsterdam, the Netherlands for their assistance in the data management, and all Hokusai VTE investigators for their contribution to the trial.

Conflict of interest: L.F.M. Beenen has nothing to disclose. L.J.J. Scheres has nothing to disclose. J. Stoker has nothing to disclose. S. Middeldorp reports grants and personal fees from Daiichi Sankyo, during the conduct of the study; and grants and personal fees from Aspen and Bayer, and personal fees from BMS-Pfizer, Boehringer Ingelheim, Portola and Sanofi, outside the submitted work. All fees were paid to the author's institution.

\section{References}

1 Benjamin EJ, Virani SS, Callaway CW, et al. Heart disease and stroke statistics - 2018 update: a report from the American Heart Association. Circulation 2018; 137: e67-e492.

2 Wattanakit K, Lutsey PL, Bell EJ, et al. Association between cardiovascular disease risk factors and occurrence of venous thromboembolism. A time-dependent analysis. Thromb Haemost 2012; 108: 508-515.

$3 \mathrm{Mi} \mathrm{Y}$, Yan $\mathrm{S}$, Lu $\mathrm{Y}$, et al. Venous thromboembolism has the same risk factors as atherosclerosis: a PRISMA-compliant systemic review and meta-analysis. Medicine 2016; 95: e4495.

4 Stein PD, Beemath A, Olson RE. Obesity as a risk factor in venous thromboembolism. Am J Med 2005; 118 : 978-980.

5 Gregson J, Kaptoge S, Bolton T, et al. Cardiovascular risk factors associated with venous thromboembolism. JAMA Cardiol 2019; 4: 163-173.

6 Braekkan SK, Siegerink B, Lijfering WM, et al. Role of obesity in the etiology of deep vein thrombosis and pulmonary embolism: current epidemiological insights. Semin Thromb Hemost 2013; 39: 533-540.

7 Rocca B, Fox KAA, Ajjan RA, et al. Antithrombotic therapy and body mass: an expert position paper of the ESC Working Group on Thrombosis. Eur Heart J 2018; 39: 1672-1686f.

8 Martin K, Beyer-Westendorf J, Davidson BL, et al. Use of the direct oral anticoagulants in obese patients: guidance from the SSC of the ISTH. J Thromb Haemost 2016; 14: 1308-1313.

9 Konstantinides S, Torbicki A. Management of venous thrombo-embolism: an update. Eur Heart J 2014; 35: 2855-2863.

10 Global BMIMC, Di Angelantonio E, Bhupathiraju Sh N, et al. Body-mass index and all-cause mortality: individual-participant-data meta-analysis of 239 prospective studies in four continents. Lancet 2016; 388: 776-786.

11 Buller HR, Decousus H, Grosso MA, et al. Edoxaban versus warfarin for the treatment of symptomatic venous thromboembolism. N Engl J Med 2013; 369: 1406-1415.

12 Beenen LFM, Bossuyt PMM, Stoker J, et al. Prognostic value of cardiovascular parameters in computed tomography pulmonary angiography in patients with acute pulmonary embolism. Eur Respir J 2018; 52: 1702611.

13 Wang ZJ, Zhou YJ, Galper BZ, et al. Association of body mass index with mortality and cardiovascular events for patients with coronary artery disease: a systematic review and meta-analysis. Heart 2015; 101: 1631-1638.

14 Qin W, Liu F, Wan C. A U-shaped association of body mass index and all-cause mortality in heart failure patients: a dose-response meta-analysis of prospective cohort studies. Cardiovasc Ther 2017; 35: https:/www.doi. org/10.1111/1755-5922.12232

15 Taylor JA, Christenson RH, Rao K, et al. B-type natriuretic peptide and N-terminal pro B-type natriuretic peptide are depressed in obesity despite higher left ventricular end diastolic pressures. Am Heart J 2006; 152: 1071-1076.

16 Poirier P, Giles TD, Bray GA, et al. Obesity and cardiovascular disease: pathophysiology, evaluation, and effect of weight loss. Arterioscler Thromb Vasc Biol 2006; 26: 968-976. 
17 Chahal H, McClelland RL, Tandri H, et al. Obesity and right ventricular structure and function: the MESA-Right Ventricle study. Chest 2012; 141: 388-395.

18 Goldhaber SZ, Savage DD, Garrison RJ, et al. Risk factors for pulmonary embolism. The Framingham study. Am J Med 1983; 74: 1023-1028.

19 Barba R, Zapatero A, Losa JE, et al. Body mass index and mortality in patients with acute venous thromboembolism: findings from the RIETE registry. J Thromb Haemost 2008; 6: 595-600.

20 Laporte S, Mismetti P, Decousus H, et al. Clinical predictors for fatal pulmonary embolism in 15,520 patients with venous thromboembolism: findings from the Registro Informatizado de la Enfermedad TromboEmbolica venosa (RIETE) Registry. Circulation 2008; 117: 1711-1716.

21 Stein PD, Matta F, Goldman J. Obesity and pulmonary embolism: the mounting evidence of risk and the mortality paradox. Thromb Res 2011; 128: 518-523.

22 Galyfos G, Geropapas GI, Kerasidis S, et al. The effect of body mass index on major outcomes after vascular surgery. J Vasc Surg 2017; 65: 1193-1207.

23 Elagizi A, Kachur S, Lavie CJ, et al. An overview and update on obesity and the obesity paradox in cardiovascular diseases. Prog Cardiovasc Dis 2018; 61: 142-150.

24 Saab J, Salvatore SP. Evaluating the cause of death in obese individuals: a ten-year medical autopsy study. $J$ Obes 2015; 2015: 695374.

25 Rosenfeld HE, Tsokos M, Byard RW. The association between body mass index and pulmonary thromboembolism in an autopsy population. J Forensic Sci 2012; 57: 1336-1338.

26 Delluc A, Le Moigne E, Tromeur C, et al. Site of venous thromboembolism and prothrombotic mutations according to body mass index. Results from the EDITH study. Br J Haematol 2011; 154: 486-491.

27 Egermayer P. Obesity, oral contraceptives, and fatal pulmonary embolism. N Z Med J 2001; 114: 170-171.

28 Sundell IB, Nilsson TK, Ranby M, et al. Fibrinolytic variables are related to age, sex, blood pressure, and body build measurements: a cross-sectional study in Norsjo, Sweden. J Clin Epidemiol 1989; 42: 719-723.

29 Davidson BL, Buller HR, Decousus H, et al. Effect of obesity on outcomes after fondaparinux, enoxaparin, or heparin treatment for acute venous thromboembolism in the Matisse trials. J Thromb Haemost 2007; 5 $1191-1194$.

30 Linnemann B, Zgouras D, Schindewolf $\mathrm{M}$, et al. Impact of sex and traditional cardiovascular risk factors on the risk of recurrent venous thromboembolism: results from the German MAISTHRO registry. Blood Coagul Fibrinolysis 2008; 19: 159-165.

31 Di Nisio M, Vedovati MC, Riera-Mestre A, et al. Treatment of venous thromboembolism with rivaroxaban in relation to body weight. A sub-analysis of the EINSTEIN DVT/PE studies. Thromb Haemost 2016; 116: 739-746.

32 Vuckovic BA, Cannegieter SC, van Hylckama Vlieg A, et al. Recurrent venous thrombosis related to overweight and obesity: results from the MEGA follow-up study. J Thromb Haemost 2017; 15: 1430-1435.

33 Eichinger S, Hron G, Bialonczyk C, et al. Overweight, obesity, and the risk of recurrent venous thromboembolism. Arch Intern Med 2008; 168: 1678-1683.

34 Prandoni P, Barbar S, Milan M, et al. The risk of recurrent thromboembolic disorders in patients with unprovoked venous thromboembolism: new scenarios and opportunities. Eur J Intern Med 2014; 25: 25-30.

35 Joshy G, Korda RJ, Attia J, et al. Body mass index and incident hospitalisation for cardiovascular disease in 158 546 participants from the 45 and Up study. Int J Obes (Lond) 2014; 38: 848-856.

36 Jimenez S, Ruiz-Artacho P, Merlo M, et al. Risk profile, management, and outcomes of patients with venous thromboembolism attended in Spanish emergency departments: the ESPHERIA registry. Medicine 2017; 96: e8796.

37 Barba R, Marco J, Martin-Alvarez H, et al. The influence of extreme body weight on clinical outcome of patients with venous thromboembolism: findings from a prospective registry (RIETE). J Thromb Haemost 2005; 3 856-862.

38 Cushman M, Creager MA. Improving awareness and outcomes related to venous thromboembolism. JAMA 2015 314: 1913-1914.

39 Kushnir M, Choi Y, Eisenberg R, et al. Efficacy and safety of direct oral factor Xa inhibitors compared with warfarin in patients with morbid obesity: a single-centre, retrospective analysis of chart data. Lancet Haematol 2019; 6: e359-e365.

40 Yang G, De Staercke C, Hooper WC. The effects of obesity on venous thromboembolism: a review. Open J Prev Med 2012; 2: 499-509.

41 Drife J. Deep venous thrombosis and pulmonary embolism in obese women. Best Pract Res Clin Obstet Gynaecol 2015; 29: 365-376. 